\title{
WORK-RELATED HEALTH EMERGENCY CASES DUE TO HYDROFLUORIC ACID EXPOSURES REPORTED TO TEXAS POISON CENTERS
}

\author{
MATHIAS B. FORRESTER \\ Department of State Health Services, Austin (TX), USA
}

\begin{abstract}
Objectives: Hydrofluoric acid is used in a number of industries. Work-related accidents involving hydrofluoric acid can result in serious injury and death. The intent of this investigation was to describe work-related hydrofluoric acid exposures in Texas. Materials and Methods: Work-related hydrofluoric acid exposures reported to Texas poison centers during 2000-2010 were identified. The distribution of exposures was determined for various demographic and clinical factors. Results: There were 409 work-related hydrofluoric acid exposures in years 2000-2010. The number of work-related exposures declined from 69 in 2000 to 18 in 2010. The patients were $85.3 \%$ male and $96.6 \%$ age 20 years or older. The distribution of cases by route of exposure was $69.4 \%$ dermal contact, $21.0 \%$ inhalation, $12.0 \%$ ocular, and $3.7 \%$ ingestion. At the time of reporting to Texas poison centers, the patient was already at or en route to a health care facility in $71.9 \%$ of the cases and referred to a healthcare facility in $20.5 \%$ of the cases. The medical outcome was known or expected to be not serious in $51.6 \%$ of the cases. Conclusions: Hydrofluoric acid exposures reported to Texas poison centers decreased over the eleven-year period. The patients were almost all adults and primarily male. Most of the exposures occurred by dermal contact followed by inhalation. The majority of patients were managed at healthcare facilities. Slightly over half of the exposures were known or expected to not result in serious outcomes.
\end{abstract}

Key words:

Hydrofluoric acid, Work-related exposure, Treatment, Outcomes, Poison centres

\section{INTRODUCTION}

Hydrofluoric acid (HF), also known as hydrogen fluoride, fluoric acid, hydrofluoride, and fluorine monohydride, is an extremely corrosive inorganic acid. It is a colorless liquid or gas with a strong odor. Hydrofluoric acid is used mostly in industrial settings such as etching and polishing glass and enamel, electronics, semiconductor manufacturing, and petroleum refineries [1,2]. It also can be found in consumer products such as those for automotive cleaning, rust removal, and water spot removal [1].
Human exposure to hydrofluoric acid occurs primarily through dermal contact, although it can occur by other routes as well [1]. Dermal contact can result in dermal pain, erythema, edema, and burns $[1,3,4]$. Inhalation can lead to mucous membrane irritation, cough, narrowing and swelling of the throat, and pulmonary edema. Ocular exposure can result in eye burns and irritation [1]. Ingestion can lead to corrosive injury to the gastrointestinal system, nausea, vomiting, diarrhea, and abdominal pain [1,3]. Systemic effects from hydrofluoric acid exposure include hypocalcemia, hypomagnesemia, hyperkalemia, and cardiac

Funding for this research was provided by a public health emergency preparedness grant (2U90TP617001-11) from the Centers for Disease Control and Prevention. Received: January 28, 2012, Accepted: July 19, 2012.

Address reprint request to M.B. Forrester, Epidemiology and Disease Surveillance Unit, Texas Department of State Health Services, 1100 W 49th Street, Austin, Texas 78756, USA (e-mail: mathias.forrester@dshs.state.tx.us). 
arrhythmia [1,3]. Deaths have been reported with adverse contact with hydrofluoric acid [5,6]. Primary treatment of hydrofluoric acid exposures involves decontamination by flushing or dilution with water and application of calcium gluconate-containing products $[1,4]$.

Information on work-related hydrofluoric acid accidents in the United States is limited. Previous studies have used as data sources Hazardous Substance Emergency Events Surveillance (HSEES) systems, Occupational Safety and Health Administration (OSHA) summaries, Consumer Product Safety Commission (CPSC) reports, American Association of Poison Control Centers (AAPCC) annual reports, and literature case reports [5,6]. United States poison centers are telephone consultation services that assist in the management of potentially adverse exposures to a wide variety of substances such as medications, illicit drugs, household products, industrial chemicals, plants, animals, and food. During 2009, 1069 hydrofluoric acid exposures were reported to United States poison centers, although all of these were not work-related exposures [7]. Several previous studies have examined hydrofluoric acid exposures reported to poison centers $[3,4,8]$. However, none of these studies focused on work-related exposures. The objective of this investigation was to describe the pattern of work-related hydrofluoric acid exposures reported to poison centers during a recent eleven-year period.

\section{MATERIALS AND METHODS}

Data for this investigation were obtained from the Texas Poison Center Network (TPCN), six poison centers located in Amarillo, Dallas, El Paso, Galveston, San Antonio, and Temple that together service the entire state, a population of over twenty million. The Texas poison centers use a single electronic database to collect demographic and clinical information on all calls they receive. The data fields and allowable codes are defined by the American Association of Poison Control Centers (AAPCC).
Cases were all work-related hydrofluoric acid exposures (accidents and otherwise) reported to the TPCN during 2000-2010. According to the AAPCC National Poison Data System (NPDS) C Reference Manual, the definition for exposure is "actual or suspected contact with any substance which has been ingested, inhaled, absorbed, applied to, or injected into the body." This definition includes "exposures to nontoxic substances (if someone was concerned enough to call to inquire about toxicity" and "exposures to toxic substances which, because of the amount involved or treatment rendered, do not cause clinical effects". Although most hydrofluoric acid exposures were likely to be unintentional (accidental), some might be intentional (suspected attempted suicide, misuse, abuse, malicious intent), and adverse reactions. An exposure might not be an emergency and might not require medical attention. This is the definition of exposure used in this investigation although it may differ from the concept of exposure as conventionally used in occupational health or medicine. A hydrofluoric acid exposure was defined as any exposure involving a substance assigned the Generic substance code 0118000 (hydrofluoric acid), 0118280 (rust remover: hydrofluoric acid), or 0201007 (wheel cleaner: hydrofluoric acid/bifluoride). The exposure was considered to be work-related if the circumstances of (reason for) the exposure was defined as "unintentional occupational" or the exposure site was defined as the "workplace".

The distribution of exposures was determined for the year, month, caller location, patient gender and age, route, whether one or more persons were involved in a particular exposure, management site, medical outcome, and most common listed adverse clinical effects and treatments. The caller may be the person who was exposed, a friend or family member, or a healthcare provider. The person usually calls the poison center because he/she is concerned about potentially adverse effects from the exposure and wants to know how to manage or treat the exposure. The caller location is listed in the TPCN as the caller's 
address. The caller's county was used to assign all possible cases to the eleven Public Health Regions (groups of counties) into which Texas is divided. The distribution by Public Health Region was then analyzed by calculation of the percent distribution and rate per 100000 population based on the 2000 Census. The management site is the location where the patient received treatment, if any. In general, the management site may be on site (that is, where the patient was at the time of the call such as his/ her workplace or home) or may be a healthcare facility. The patient may already be at or en route to a healthcare facility when the poison center was contacted or may be referred to a healthcare facility by the poison center.

The medical outcome or severity of an exposure is determined by the poison center staff managing the patient and is based on the observed or anticipated adverse clinical effects. Medical outcome is classified according to the following criteria: no effect (no symptoms due to exposure), minor effect (some minimally troublesome symptoms), moderate effect (more pronounced, prolonged symptoms), major effect (symptoms that are life-threatening or cause significant disability or disfigurement), and death. All exposures are not followed to a final medical outcome because of resource constraints or the inability to find subsequent information on the patient. For those exposures not followed to a final medical outcome, the poison center staff record the expected outcome of the exposure. These expected outcomes are grouped into the following categories: not followed but judged as nontoxic exposure (symptoms not expected), not followed but minimal symptoms possible (no more than minor symptoms possible), unable to follow but judged as a potentially toxic exposure. Another medical outcome category is unrelated effect where the exposure was probably not responsible for the symptoms.

The Texas Department of State Health Services institutional review board considers this analysis exempt from ethical review.

\section{RESULTS}

Of 1007 total hydrofluoric acid exposures reported to Texas poison centers during 2000-2010, 409 (40.6\%) were considered work-related exposures. The annual number of reported exposures tended to decline over the elevenyear period (Table 1). There was no seasonal pattern to the exposures. The distribution of exposures by Texas Public Health Region is presented in Table 2. The rate per 100000 population varied between 0.71 and 3.24 with no geographic pattern.

Males accounted for 349 (85.3\%) of the exposures, females for 57 (13.9\%), and unknown gender for $3(0.7 \%)$. Eight $(2.0 \%)$ of the patients were less than 20 years in age, 395 (96.6\%) were 20 years or older, and $6(1.5 \%)$ of unknown age. For those patients where the exact age in years was known, the mean age was 36 years (range 16-73 years). The circumstances of or reason for the exposure was unintentional or accidental in 973 (96.6\%) cases, intentional in $25(2.5 \%)$, adverse reaction in $2(0.2 \%)$, and unknown in $7(0.7 \%)$.

The route of the exposure was dermal in $284(69.4 \%)$ cases, inhalation in $86(21.0 \%)$, ocular in $49(12.0 \%)$,

Table 1. Annual number of work-related hydrofluoric acid exposures reported to the Texas Poison Center Network during 2000-2010

\begin{tabular}{|c|c|}
\hline Year & $\begin{array}{c}\text { Exposures } \\
\mathrm{n}\end{array}$ \\
\hline 2000 & 69 \\
\hline 2001 & 50 \\
\hline 2002 & 34 \\
\hline 2003 & 47 \\
\hline 2004 & 36 \\
\hline 2005 & 28 \\
\hline 2006 & 42 \\
\hline 2007 & 28 \\
\hline 2008 & 39 \\
\hline 2009 & 18 \\
\hline 2010 & 18 \\
\hline Total & 409 \\
\hline
\end{tabular}


Table 2. Work-related hydrofluoric acid exposures reported to the Texas Poison Center Network during 2000-2010 by Public Health Region where the call originated

\begin{tabular}{lcrrc}
\hline \multirow{2}{*}{$\begin{array}{c}\text { Public Health Region } \\
\text { (area: major cities) }\end{array}$} & $\begin{array}{c}\text { Population }^{1} \\
\text { (total) }\end{array}$ & \multicolumn{2}{c}{ Exposures } & \multirow{2}{*}{$\begin{array}{c}\text { Rate/1,000,000 } \\
\text { population }\end{array}$} \\
\cline { 3 - 4 } & $\mathrm{n}$ & $\mathrm{n}$ & $\%$ & 1.92 \\
1 (Northeast: Amarillo, Lubbock) & 780733 & 15 & 3.8 & 1.46 \\
2 (North-central: Abilene, Wichita Falls) & 549267 & 8 & 2.0 & 1.97 \\
3 (North-central: Dallas, Fort Worth) & 5487477 & 108 & 27.0 & 2.26 \\
4 (Northeast) & 1015648 & 23 & 5.8 & 3.24 \\
5 (East) & 740952 & 24 & 6.0 & 1.48 \\
6 (Southeast: Houston) & 4854454 & 72 & 18.0 & 2.81 \\
7(Central: Austin) & 2309972 & 65 & 16.3 & 1.86 \\
8 (South-central: San Antonio) & 2146154 & 40 & 10.0 & 2.67 \\
9 (West-central) & 524884 & 14 & 3.5 & 0.71 \\
10 (West: El Paso) & 704318 & 5 & 1.3 & 1.50 \\
11 (South: Corpus Christi, Brownsville) & 1737961 & 26 & 6.5 & 1.92 \\
Total known & 20851820 & 400 & 100.0 & \\
\hline
\end{tabular}

${ }^{1}$ According to 2000 Census.

Public Health Region was based on the caller county. Four calls originated outside of Texas and five cases had an unknown caller county.

Table 3. Management site and medical outcome of work-related hydrofluoric acid exposures reported to the Texas Poison Center Network during 2000-2010

\begin{tabular}{|c|c|c|}
\hline \multirow{2}{*}{ Variable } & \multicolumn{2}{|c|}{ Exposures } \\
\hline & $\mathrm{n}$ & $\%$ \\
\hline \multicolumn{3}{|l|}{ Management site } \\
\hline On site (example, at work) & 29 & 7.1 \\
\hline Referred to healthcare facility & 84 & 20.5 \\
\hline Already at/en route to healthcare facility & 294 & 71.9 \\
\hline Unknown & 2 & 0.5 \\
\hline \multicolumn{3}{|l|}{ Medical outcome } \\
\hline No effect & 25 & 6.1 \\
\hline Minor effect & 144 & 35.2 \\
\hline Moderate effect & 114 & 27.9 \\
\hline Major effect & 12 & 2.9 \\
\hline Death & 2 & 0.5 \\
\hline Not followed - judged nontoxic & 3 & 0.7 \\
\hline Not followed - minimal effects possible & 39 & 9.5 \\
\hline Unable to follow - potentially toxic & 66 & 16.1 \\
\hline Unrelated effect & 4 & 1.0 \\
\hline Not serious $^{1}$ & 211 & 51.6 \\
\hline Serious $^{2}$ & 194 & 47.4 \\
\hline Total & 409 & \\
\hline
\end{tabular}

Management site is the location where the patient received treatment, if any.

${ }^{1}$ No effect, minor effect, not followed and judged nontoxic or minimal effects possible.

${ }^{2}$ Moderate effect, major effect, death, unable to follow and potentially toxic. 
Table 4. Most common adverse clinical effects associated with work-related hydrofluoric acid exposures reported to the Texas Poison Center Network during 2000-2010

\begin{tabular}{|c|c|c|}
\hline \multirow{2}{*}{ Adverse clinical effect } & \multicolumn{2}{|c|}{ Exposures } \\
\hline & $\mathrm{n}$ & $\%$ \\
\hline Dermal irritation/pain & 206 & 50.4 \\
\hline Erythema/flushed & 74 & 18.1 \\
\hline Burns (superficial) & 70 & 17.1 \\
\hline Ocular irritation/pain & 46 & 11.2 \\
\hline Burns (2nd-3rd degree) & 35 & 8.6 \\
\hline Cough/choke & 29 & 7.1 \\
\hline Edema & 26 & 6.4 \\
\hline Dyspnea & 23 & 5.6 \\
\hline Throat irritation & 19 & 4.6 \\
\hline Headache & 16 & 3.9 \\
\hline Red eye & 14 & 3.4 \\
\hline Total & 409 & \\
\hline
\end{tabular}

ingestion in $15(3.7 \%)$, and other in $3(0.7 \%)$. Some of the exposures occurred by multiple routes.

A single individual was involved in 371 (90.7\%) of the exposures. Of the $38(9.3 \%)$ individuals involved in multipleperson exposures, there were seven incidents involving two individuals and one each incidents involving three, five, seven, and nine individuals. Additional substances were reported to be involved in 55 (13.4\%) of the exposures.

Table 3 shows the distribution of work-related hydrofluoric acid exposures by management site and medical outcome. The majority of patients were already at or en route to a healthcare facility when the poison center was contacted, and most of the remainder were referred to a healthcare facility by the poison center. The majority of exposures were known or expected to result in outcomes that were not serious. Two of the exposures were known to have resulted in death.

Dermal irritation or pain was reported in $50.4 \%$ of the exposures (Table 4). Most of the other frequently reported adverse clinical effects were dermal, respiratory, or ocular in nature. Table 5 presents the most frequently reported specific treatments. Dilution/irrigation/wash and calcium were reported to have been used or recommended in over half of the exposures.

Table 5. Most common treatments associated with work-related hydrofluoric acid exposures reported to the Texas Poison Center Network during 2000-2010

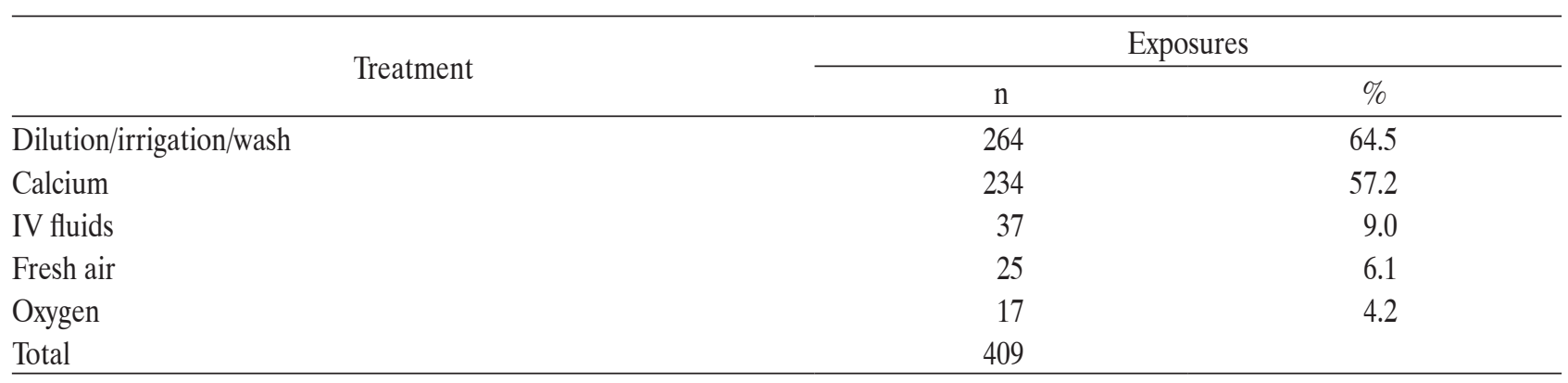




\section{DISCUSSION}

This investigation describes the pattern of work-related hydrofluoric acid exposures reported to Texas poison centers that serve a population of over twenty million during a recent eleven-year period. Such information is important because hydrofluoric acid is used in a number of industries [1,2]. Moreover, work-related accidents involving hydrofluoric acid can result in serious injury and death $[1,3,4]$. Such information may be particularly important in Texas. In a previous study of hydrofluoric acid releases that used data from HSEES systems in 17 states, the highest proportion of releases were reported from Texas [5].

This study is subject to certain limitations. Reporting of work-related hydrofluoric acid exposures to Texas poison centers is not mandatory. Those exposures that are reported may not be representative of all such exposures that occur in the state. Moreover, exposure to hydrofluoric acid was based on reports provided by the caller who may be the patient, a friend, or family member and were not necessarily independently confirmed.

The annual number of reported work-related hydrofluoric acid exposures declined over the eleven-year period. This may have resulted from a decrease in total workrelated hydrofluoric acid exposures. Unfortunately, such information is not readily available. The decline in reported exposures also could have been due to a decrease in exposures that resulted in potentially adverse effects that would be reported to poison centers or a decrease in the tendency to contact Texas poison centers about such exposures.

There was no clear geographic pattern to the distribution of work-related hydrofluoric acid exposures. This suggests that those occupations and industries that use hydrofluoric acid and may result in potentially adverse exposures are spread throughout the state and not concentrated in one or more specific areas.
The majority of the patients were male. This is consistent with the study of work-related hydrofluoric acid exposures reported to HSEES systems where $85 \%$ of the victims were male [5]. In addition, a study of all hydrofluoric acid exposures reported to a poison center in Sweden observed $84 \%$ of its patients to be male [8].

Almost all of the patients were adults, and the youngest with a known age was 16 years. This appears to indicate that work-related hydrofluoric acid accidents involving minors might be relatively rare in Texas.

The most common route of work-related hydrofluoric acid exposure was dermal followed by inhalation and ocular with relatively few involving ingestion. This would suggest that efforts to prevent and manage work-related hydrofluoric acid exposures should focus on dermal, inhalation, and ocular exposures and to a lesser extent ingestions.

Although $87 \%$ of the exposures were reported to involve only hydrofluoric acid, $13 \%$ involved other substances. Since other substances might affect the management of patients, those treating victims of work-related hydrofluoric acid exposures might want to ascertain whether other substances were involved in the exposure.

Ninety-one percent of the patients were exposed to the hydrofluoric acid by themselves. In contrast, the investigation using HSEES system data found that $47 \%$ of the incidents involved one victim [5]. This dissimilarity may reflect differences in the data sources between the two studies.

The majority of patients were seen at a healthcare facility or referred to a healthcare facility by the poison center. This might be expected considering the potentially severe outcome of hydrofluoric acid exposure and is consistent with previous studies $[5,8]$. However, slightly more than half the exposures were known or expected to result in outcomes that were not serious. It might be argued that at least a portion of those patients without serious outcomes who were already at or en route to healthcare 
facilities when the poison centers were contacted might have been successfully managed by the poison centers without incurring the expense of healthcare facility visits. However, the treatment provided by the healthcare facilities may have prevented more serious outcomes from manifesting.

Dermal irritation or pain was reported in over half of the exposures, and many of the other most frequently reported adverse clinical effects were dermal in nature. This is to be expected considering the majority of exposures occurred via dermal contact. The particular adverse clinical effects observed in this study were consistent with the literature $[1,3,4]$.

The most common reported treatments were dilution/ irrigation/wash and administration of calcium. These methods of treatment were compatible with the literature $[1,4]$.

In conclusion, hydrofluoric acid exposures reported to Texas poison centers decreased over the eleven-year period. The patients were almost all adults and primarily male. Most of the exposures occurred by dermal contact followed by inhalation. The majority of patients were managed at healthcare facilities. Slightly over half of the exposures were known or expected to not result in serious outcomes.

\section{REFERENCES}

1. Agency for Toxic Substances and Disease Registry. Hydrogen fluoride (HF). Atlanta: Agency for Toxic Substances and Disease Registry [cited on October 25, 2011]. Available at URL: http://www.atsdr.cdc.gov/mmg/mmg.asp?id=1142\&tid=250.

2. Bertolini JC. Hydrofluoric acid: A review of toxicity. J Emerg Med 1992;10:163-8.

3. Kao WF, Dart RC, Kuffner E, Bogdan G. Ingestion of lowconcentration hydrofluoric acid: an insidious and potentially fatal poisoning. Ann Emerg Med 1999;34:35-41.

4. el Saadi MS, Hall AH, Hall PK, Riggs BS, Augenstein WL, Rumack BH. Hydrofluoric acid dermal exposure. Vet Hum Toxicol 1989;31:243-7.

5. Horton DK, Berkowitz Z, Kaye WE. Hydrofluoric acid releases in 17 states and the acute health effects associated, 1993-2001. J Occup Environ Med 2004;46:501-8.

6. Blodgett DW, Suruda AJ, Crouch BI. Fatal unintentional occupational poisonings by hydrofluoric acid in the U.S. Am J Ind Med 2001;40:215-20.

7. Bronstein AC, Spyker DA, Cantilena LR, Green JL, Rumack BH, Giffin SL. 2009 annual report of the American Association of Poison Control Centers' National Poison Data System (NPDS): 27th annual report. Clin Toxicol (Phila) 2010;48:979-1178.

8. Hulten P, Hojer J. Hydrofluoric acid - experiences of 157 exposures 2003-2008. Clin Toxicol (Phila) 2010;48:315.

This work is available in Open Access model and licensed under a Creative Commons Attribution-NonCommercial 3.0 Poland License - http://creativecommons.org/ licenses/by-nc/3.0/pl/deed.en. 